\title{
Sexual Violence and Gender Equality in Grassroots Music Venues: How to Facilitate Change
}

\author{
Rosemary Lucy Hill \\ University of Huddersfield \\ r.l.hill@hud.ac.uk
}

Molly Megson

University of Huddersfield

m.j.megson@hud.ac.uk

\begin{abstract}
Sexual violence in the music industry is known to impact negatively on women's participation. We examine how grassroots venues and promoters can implement changes to tackle sexual violence and work towards gender equality. We draw on UK-based, impact-focused research which sought to raise awareness of sexual violence, and to facilitate anti-violence changes within organisations. We find that working across a city's music scene and engaging with oversight organisations such as local authorities can aid in persuading venues and promoters to seek training. However, for individuals leading on changes, personal experiences of sexual violence as a victim/survivor or bystander are important factors in their decision. We conclude that men in the music industry need to become more aware of the need for change, and willing to act on that awareness; and that more women need to own, manage, and run venues and events.
\end{abstract}

KEYWORDS: Grassroots music industry, live music, music venues, prevention, sexual violence

\section{Introduction}

Sexual violence in the music industry is an under-researched area, but we know that it occurs and can impact negatively on women's participation. Kesha's suit against producer Dr. Luke for sexual violence and emotional abuse is welldocumented (e.g. Johnston, 2016). Swedish newspaper Dagens Nyheter published 2912 women's personal accounts of the sexual assaults they have faced in their 
music careers (Dagens Nyheter, 2017). We do not know how many women and gender non-conforming people have been deterred from pursuing careers in music due to men's sexual violence, as much of the research around musicianship focuses on success stories. Furthermore, many of important spaces which are critical to the development of music careers - such as grassroots live music scenes - are typically male dominated (Webster et al., 2018); and as reported in our previous research are sadly, spaces in which sexual assaults occur (Hill et al., 2020). As we have previously examined, assaults significantly affect women audience members and musicians, and impact negatively on venue reputations (Hill et al., 2020). Indicative of the significance of the issue, it has also featured prominently in media reporting over the last four years (BBC News, 2018; Madden, 2019; O'Connor, 2017) and resulted in the establishment of a range of anti-violence organisations focusing specifically on the live music space. For example, grassroots organisations such as Girls Against Gig Groping (GAGG) (2020) and Safe Gigs For Women (SGFW) (2017), both based in the UK, have emerged with the aim of raising awareness about sexual violence at live music events. London based Good Night Out Campaign (GNO) (2020) trains venues, pubs, bars, and clubs in how to respond to sexual violence. In Australia, Victoria state set up a taskforce on sexual violence in the night-time economy in Melbourne (Moskovitch, 2015); and in the USA, feminist punks in Baltimore train venues in bystander intervention (Potter, 2019). These interventions are important, but not as widespread as we might hope. Moreover, those that do exist do not always receive the ongoing support from governments that is required for longer-term success. For instance, the impact of the lack of government support for the intervention in Melbourne meant that the project stalled at the pilot stage (1). Inspired by these programmes of change, we worked with the grassroots music industry in one English city (Leeds) and one nearby town (Huddersfield) to understand what might work in persuading and enabling music venues and promoters to make changes around training, policy, and procedure to reduce sexual harassment and violence, and to respond more sensitively to incidents.

This article examines the impact of our project to understand what enables music venues and promoters to make changes, and what barriers and challenges need to be overcome. Our larger goal is to explore the role of anti-violence work in changing music culture and fostering a more welcoming environment for women and gender non-conforming people as audiences, musicians, sound engineers, and in other live music roles. Violence plays a part in limiting women's lives (VeraGray, 2017), the lives of those who do not conform to heteronormative ideals of gender (Butler, 1993), and ultimately maintains male dominance (Hester et al., 1996). Reducing sexual violence should be a key goal in working towards gender equality in the music industry. As we argue in this paper, in order to work towards gender equality in grassroots music scenes, venues and promoters need to take responsibility for preventing and responding appropriately to sexual violence at their events. As we explore, a culture in which sexual violence is de-normalised, believing victim/survivors, and responding with care to reduce the likelihood of retraumatisation is vital to achieving this sense of responsibility. Further, we posit that two factors are significant in generating this: (one) community-wide discussion, and (two) personal experience of violence. We argue that these are significant across three levels of engagement: (one) the city-wide and regional scene, (two) relationships with local authorities (local government) and music industry oversight bodies, and (three) individuals in venues and promotions organisations. 
We begin this paper by considering relevant literature, and then outline our methodology. We then briefly discuss the kinds of action available to venues and promoters, and summarise the changes made by our research participants. We then analyse three key enablers in the decision-making process: discussion across the local music community; engagement with local authorities and music industry oversight bodies; driven individuals.

\section{Background and context Gender and the music industry}

It is widely accepted that sexism and inequalities exist within the music industry. In reviewing research on the music industry, Strong and Raine (2018: 2) argue that this gender inequality is "extreme". This is further evident when examining recent work on the UK music industry by Vick Bain (2019) who provides detail to this inequality, revealing that men signed to publishers outnumber women by $6: 1$, and men signed to labels outnumber women by 5:1. Yet the 'industry' - institutions, organisations, spaces (venues, studios, rehearsal rooms), networks, and nonmusician roles - has received little attention in comparison to that directed towards performers (drawing on Leonard, 2016). Despite this, there is an ethos within the music industry devoted to values of fairness, equality, and inclusion. This is yet to translate into wholesale feminist activity or change (Bennett, 2018); however, as Conor, Gill and Taylor (2015) demonstrate, there are numerous ways in which women, Black Asian and Minority Ethic (BAME), and even working-class men are disadvantaged in the cultural and creative industries, a sad list to which we might also add gender and sexuality non-conforming people (Pearce and Lohmann, 2019; Sharp and Nilan, 2017), and disabled people (Lubet, 2011). Informal networks and hiring practices also privilege middle-class, straight, white men (Conor et al., 2015); ideals of the creative individual match masculine norms more closely than feminine norms (Battersby, 1989); and everyday sexism impacts on women's confidence and feelings of inclusion (Vera-Gray, 2017). Sexual harassment, exploitation, and abuse are regarded as "endemic" (Mackenzie, 2017; cited in Bennett, 2018: 31) for female musicians, and have a long, though little documented, history (Timonen, 2018). Our previous work (Hill et al., 2020) has also shown that sexual assault in the live music audience has been normalised and silenced, with venue managers typically unequipped to deal with incidents when they are brought to their attention. These conditions produce a music industry which is less than friendly to women participants, whether they are working or seeking musical pleasure. A survey of members by the UK Musicians' Union found, for example, that $48 \%$ of its female members have suffered sexual harassment, the majority of whom did not report it for fear of losing work (Musicians' Union, 2019). Meanwhile, a YouGov poll shows one third of UK women have experienced sexual assault at festivals (BBC News, 2018), whilst work examining Australian festivals reveals multiple barriers to reporting sexual violence (e.g. misunderstanding that an assault is a criminal offence, rape myths that obscure crimes committed by acquaintances, fear of being perceived as "asking for it" due to dress or inebriation, shame, fear of being blamed) (Fileborn et al., 2020), illuminating part of the difficulty in gaining accurate data. Nonetheless, we know that sexual violence is occurring at festivals, and that this is an international problem (Platt and Finkel, 2020).

One attempt to address the issues, has seen the UK Musician's Union (n.d.) develop a sexual harassment reporting tool and associated campaign to ensure that musicians are included in new laws to instigate a duty of care on employers to 
prevent sexual harassment amongst their staff. Campaigning organisations SGFW and GAGG also raise the issue of sexual violence amongst audience members, both partnering with bands, venues, and, in the case of SGFW, a music awards ceremony, with the aim of reducing incidents. GNO train pub, club, and venue staff in how to deal sensitively with incidents, advising on policy and law. White Ribbon (WR), a global anti-violence charity highlighting men's violence against women, also have an accreditation and action plan for venues to assist in the reduction of violence. These organisations are new (most started in 2015) and there is no research on their effectiveness as anti-violence interventions nor on how they might aid progress towards women's participation in music. Meanwhile, analysis of how successful the Melbourne scheme has not been publicly released.

\section{Anti-violence work}

More broadly, implementations against sexual violence take multiple forms, which might be preventative (primary), or secondary interventions such as after-care. Interventions are directed at changing individuals, for example bystander intervention training, and men against violence programmes. Interventions aiming for change at a community level are rarer (DeGue et al., 2014). Bystander intervention focuses on making cultural change, with the goal of bystanders stepping in (Latané and Darley, 1970), with training provided to develop confidence in order to do so (Goldman and Harlow, 1993). As Flood argues "men have a vital role to play in ending men's violence against women" (2019a: 1). Implementations focusing on engagement and education of men, such as Katz's (2006) Macho Paradox, correlate sexism, masculinity, male dominance, and violence against women. Such programmes encourage men to take responsibility for changing damaging perspectives which normalise men's violence against women, and to act as allies rather than perpetuators. Hong's (2000) Men against Violence model looks at peer pressure, more equitable male and female relationships, conflict resolution, meaningful friendships with other men, anger and fear management, and challenging rape myths. It is recognised that while there is a need for men to be ready to reflect on their own privilege and masculinity, this can be challenging for some (Burrell, 2018; Flood, 2019a).

Within the context of the night-time economy, in the UK a number of antiviolence strategies have focused on protecting women by attempting to educate on what forms of behaviour may reduce the likelihood of being assaulted (e.g. keeping an eye on drinks to prevent them being spiked). These interventions have not been well-received by women, however, as they are seen as impractical and patronising, and leaving men's behaviour unchallenged (Brooks, 2011). Gunby et al. (2017) argue that bars and clubs can be useful sites to inform men about sexual violence law; however, in practice, informative posters often go unobserved and undiscussed. Furthermore, time spent in these spaces is meant to be leisure time, rather than an educational experience. Nights out are partly about "transgression and boundary pushing" (2017: 325). For male-dominated music venues, there is an additional tension where music cultures' ideologies of freedom (Grossberg, 1984) clearly impinge on the freedoms of women and gender non-conforming people, where the boundaries being transgressed are those of personal space and consent. Fileborn, Wadds and Barnes (2019) argue that the male-dominated context of the music industry creates the "cultural scaffolding" (Gavey, 2005) for sexual violence to be perpetrated. This is an important tension to recognise, as it indicates that any interventions in music venues must take the musical context into account. 
It should also be recognised that such approaches are focused on an individualistic level. They are therefore likely only to have limited success, as the systemic and organisational inequalities that enable men to commit violence remain in place. Burrell argues that to engage men successfully, interventions need a "triadic structure" (2018: 457): discussion of masculinity (culture), patriarchy (structure), and the individual (personal). Community interventions combine the factors in individualistic interventions to create a more holistic preventative approach to sexual violence, implementing change to the environmental and social conditions as well as individual skills, attitudes, and behaviours. Davis, Parks \& Cohen's (2006) spectrum of prevention details the conditions that create environments in which sexual violence occurs, and the social norms that support it. The spectrum therefore is a tool for developing a comprehensive prevention strategy around fostering norms of safe behaviour, healthy, equitable, and safe relationships, and forming a sense of a community. It is an environmental and systemic approach to change, based on six levels of activities:

1. strengthening individual knowledge and skills

2. promoting community education

3. educating providers

4. fostering coalitions and networks

5. changing organisational practices

6. influencing policies and legislation

Davis, Parks \& Cohen's approach highlights individual, organisational, and broader community-level strategies, an approach shared by Michau et al. (2015). Additionally, Michau et al. argue that success depends on using multiple strategies over time in order to build support. DeGue et al. (2014) state that interventions need to be multifaceted, multi-level, use multiple modes, involve the active participation of those being trained, and be sustained over time and in sufficient depth. Similarly, Arango et al.'s (2014) systematic review identifies a small but growing body of rigorously tested interventions, which demonstrate that preventing sexual violence is possible and can be effective. As they argue, effective interventions use multiple, well-integrated approaches, and engage with multiple stakeholders over time. Successful interventions also address underlying risk factors for violence, including social norms regarding gender dynamics and the acceptability of violence. These suggest a community-wide approach could be the most appropriate strategy for dealing with sexual violence in grassroots live music environments. However, given the stress upon the comprehensiveness, depth, and strength of community needed to be effective, we need to ask, how could such an intervention take place at the level of a city-wide or regional scene?

\section{Methodology}

In this paper, we are using a broad definition of sexual violence, as drawn from Kelly's (1988) concept of the continuum (anything that removes a woman's feeling of control over her sexual choices) and supplemented with Fileborn's (2016) theorisation that sexual violence is both material and discursive. Whilst victim/survivors of sexual violence can be of any gender, it is important to recognise that gendered power dynamics are salient: most perpetrators are men and most targets are women (Pease, 2014). Our research is underpinned by a theory of patriarchy in which gender violence both enables and maintains male dominance 
(Walby, 1990). We acknowledge that the manifestation of patriarchy is not the same everywhere, as it interacts differently with other axes of power (e.g. economic or racial dominance). Looking at localised versions of patriarchy, however, help us to understand its flexibility and adaptability (Enloe, 2017; Evans, 2017), and also the kinds of work that can be done to lessen its negative impact on women and gender non-conforming people.

The research was undertaken in 2019 and early 2020 as a follow-on project to our previous research on experiences of sexual violence at gigs, (Hill et al., 2020). The first phase of the project, conducted during 2018, examined experiences of sexual violence at gigs, and made recommendations for venue managers and promoters in order to respond to the problem. The second phase of the project, which is our focus here, aimed to understand how and why venues and promoters undertake processes of change, what aids the implementation of such changes, and the barriers which arise. Our approach has similarities with critical participatory action research (Kemmis et al., 2014), as the project sought to understand how changes can be brought about to benefit disadvantaged groups. Furthermore, it was planned in collaboration with industry partners, and they remained involved as consultants throughout the project. The research process required ongoing reflexive effort as we worked through the results of our findings, and planned each stage of our project. For example, learning from participants that sourcing funding for training was difficult, we organised interviews with local authorities to discuss potential funding streams and existing training provision. In addition, we organised two awareness-raising workshops with venues and promoters in Leeds and Huddersfield to discuss the issue, and to enable networking between venues, promoters, campaigning organisations, and local authority representatives. We also conducted surveys with audience members in venues before and after GNO training, observed training sessions, and interviewed three venue managers and two promoters who had undertaken training. Additionally, we interviewed one further venue manager who had undertaken training from a different provider, representatives from four campaigning organisations, and two local authorities, and re-interviewed three of the concert goers from our earlier research. In this paper we focus specifically on the interviews with venues and promoters.

This small-scale project has some limitations. The research team are white, relatively young and indie/rock centred, as were the local music board, Music:Leeds, who played a role in promoting the workshop in the city. Omissions in the participant invitation list meant a number of venues outside the city centre were not present. These predominantly catered to BAME and older audiences. Moreover, in being centred on sexual violence, gender was implied to be the most important axis of oppression, whereas a more intersectional approach to sexual violence in the first place might have yielded better results in attendance at the workshop and participation in subsequent research. This shows that interventions must be suited to their audiences. Most studies on sexual violence interventions reported on majority white interventions, and there remains a lack of information on interventions designed for minority ethnic groups (DeGue et al., 2014). In recognising these limitations, we did make attempts to contact some of these venues, but, lacking connections with gatekeepers in these venues, were unsuccessful. We therefore do not attempt to generalise across music scenes that focus on other genres or that exist in other parts of the UK or globally. However, our holistic approach, intending to capture multiple perspectives on what can be done about sexual violence, means that we can make some suggestions. 
In this article we focus on three practical measures available to venues and promoters in our region, which we discussed during our workshops: training by GNO, accreditation by WR, and safer spaces policies.

1. GNO training analyses current practice and develops policies adapted to the venue's needs. Interactive workshops explore key issues such as defining sexual harassment and assault, exploring barriers and enablers for action, and techniques for de-escalation and responding to trauma. Visual materials help the venue promote their accreditations and policies (Good Night Out Campaign, 2020).

2. White Ribbon work with venues and larger organisations such as police, fire, and council services. Accreditation develops a comprehensive action plan to improve gender equality and respect across the whole organisation, promoting strategic leadership to engage males. Accreditation requires employees to support women, hold perpetrators to account, challenge inappropriate behaviour, and strengthen gender equality within the wider community (White Ribbon Campaign UK, n.d.).

3. Safer spaces policies are an agreement between venue and audiences on behaviour and attitudes. Safer spaces policies set boundaries and "ground rules" for behaviour, and articulate what should be done if these are violated. Policies serve as warning to potential harassers, and reassurance to those frequenting the venue. They function as a contract of accountability between the venue and its patrons regarding physical and emotional safety (Hill and Megson, 2020).

We focus particularly on the GNO training, as, of the three measures, it was the most widely taken up by venues and promoters. Those representatives of venues, and the promoters to whom we spoke, had attended our awareness-raising workshop, and some had attended training by GNO in the previous five months.

Venue 1 was a small venue run by women as a collective. A safer spaces policy and an aim to make the venue free from discrimination had been integral to the venue since before opening, so that the ethos of safety and inclusivity was fundamental to operations. The safer space policy is available on the website, displayed in the venue, and reminders appear on every table. Venue 2, a medium sized venue, had GNO training for all staff, including their regular sound engineers. They display GNO posters in the toilets inside the venue. Six months later, they were considering writing a new policy, similar to a safe spaces policy. In the first phase of the project we spoke to a male manager, and in the second phase we spoke to a female manager, who was line-managed by the male manager. Venue 3, a small venue that is part of a national chain, had GNO training alongside another music venue in the same chain. Bar staff and managers attended the training, but door staff did not. They display GNO posters in the toilets, and we were told that a copy of the safer spaces policy sat on all of the bars in the venue, although we could not see this when we visited. In the first phase of the project we spoke to a male manager, and in the second phase we spoke to a female manager. Venue 4, a small venue specialising in club nights, had GNO training which all staff, including regular door staff, attended. They also implemented a short safer spaces policy which is available on their website. All new staff are briefed, and required to sign their safer spaces agreement. GNO posters and certificates are displayed in the venue.

Promoter 2 (2) is a professional team who also run a small record label. The organisation received GNO training and, six months later, were thinking about how 
to integrate the lessons learned into the business structure. Promoter 4, a small feminist organisation, undertook GNO training alongside a number of other smallscale promoters in the city, including Promoter 2 . They already told customers they aimed to make their gigs safer, and included a brief policy on their mail outs about gigs. They announced their GNO accreditation online.

We now turn to our findings and discuss the key factors that led these venues and promoters to implement change in order to prevent and respond well to incidents of sexual violence.

\section{Community across the music scene}

A significant persuasive factor in convincing venues and promoters to take action was the broader societal and community expectations they experienced. Expectations emerged from our awareness-raising sessions, conversations between venues and promoters, and general political attitudes of organisations and their audiences.

The awareness-raising sessions drew on our previous research (Hill et al., 2020) and were aimed specifically at venue managers and promoters. We wanted to create a space in which venues and promoters could discuss the issues with others, and share similar experiences and good practice. We hoped such peer support would reduce the chances of any defensive feelings about their specific organisations. During the workshops, we verbally reported our first phase research findings, and this was then followed by a group discussion. There were then presentations from GNO and $\mathrm{WR}$, and a talk from a venue who had previously been trained by GNO. In Leeds, the event was attended by representatives from eleven venues and nine promotions groups (29 attendees in total), as well as representatives from the Musicians Union. In Huddersfield, which is much smaller, two venues and one promotions team attended the workshop.

These workshops were successful in raising awareness of the problem and potential solutions amongst attendees. They facilitated links between venues, promoters and the two campaigning organisations. In Leeds, this led to three music venues seeking GNO training, and Music:Leeds using Arts Council money to fund training for 14 promotions groups. In Huddersfield, connections were enabled between venues and the local authority who went on to offer to fund GNO training in those two venues. Not all of the venues who attended the workshop in Leeds did go on to contact GNO, which could be due to a number of reasons. A number of these venues, however, did discuss the possibility of putting together a safer spaces policy, and we subsequently saw a new safer spaces policy put in place at one of those venues. For those venues and promoters who did access training, the conversations they had with us were key to persuading them that while there was a problem, something could be done about it. As Venue 2 said, when asked why they had decided to have training, "It was talking to you [interviewer] really that was the catalyst that just started that ball slowly moving" (Venue 2).

Fileborn (2016) argues that a strong sense of community within pubs and clubs is important in encouraging both feelings of safety and supporting bystander intervention. Our findings on increased feelings of safety within a community not only mirror Fileborn's, but also demonstrate that feelings of community work across music venues. Venues 2 and 3 similarly described how talking to not only each other but other venues as well about sexual violence and what they might do about it, resulted in a shared sense of responsibility in how to respond. Both Venue 4 and Promoter 4 spoke of the value of having a networking forum in the local music 
industry to discuss ideas, and were open to possibly making this a regular event (Venue 4).

Meanwhile, Venue 1, whose safer spaces work had been integral to the running of the venue from the beginning, described their willingness to engage in discussion about sexual violence at the workshop because this was something they saw themselves as leaders in: "this is something we can actually contribute to, this is something that we've actually got a lot of expertise in, and something that we're kind of ahead of the curve with. (Venue 1) This contrasts with their usual approach, however, which was to be somewhat distanced from the music scene in Leeds. They acknowledged that they had been "some kind of North Korea of music venues in Leeds cause we were just, like, not really communicating with anyone" (Venue 1 ). But another venue in the city (Venue 2) had been unwilling to engage with Venue 1, and expressed the view that safer spaces policies could not guarantee safety, nor were they inclusive, as they typically excluded white men. Whilst Venues 1 and 2 may not have settled their differences at the workshop, they were engaged in the same discussion. This was useful because it presented Venue 2 with a working example of a venue thinking actively and successfully about safety, opening up space for dialogue.

Local music boards helped organise and promote both workshops, utilising existing good links with music venues and promoters. This method gave us an official stamp of approval, and helped establish rapport. It demonstrates the importance of both research-informed interventions, and the value of connecting organisations to bring together music researchers and the groups they aim to speak to. As Davis et al. (2006) argue, one level of activities in the spectrum of prevention is fostering coalitions and networks. In bringing together venues and promoters to discuss the issue amongst peers, we enabled discussions between organisations that had not been in contact before regarding the sexual violence issue. We were also able to engage in another level of activity on the spectrum - promoting community education - through both the presentation of our phase one research findings and talks by GNO and WR. The workshops therefore functioned as a door opening to enable further levels of activity on the spectrum to be achieved. One very important result of the workshops was, therefore, to bring venues and promoters together so that they could speak to each other.

An additional layer of incentive for venues and promoters to participate in this research came from their view of themselves as part of the community for "progressive" (Venue 4) values. Promoter 4 and Venue 4 both described a culture of expectation that worked between themselves and bands, audience members, and venues:

We tend to work with bands that have the similar ethos to us. So I think there's a bit of a mutual expectation there that they'll expect stuff from us and we'll expect from them as well. [...] We have bands talk about it on stage as well, about what's expected of the crowd. (Promoter 4, speaking of a feminist ethos)

It's almost expected in our community that you have to uphold these standards now. People expect it. (Venue 4, speaking of dance and Peace Love Unity Respect culture (3))

This culture of expectation was deeply dependent on the philosophies and politics of the musical communities within which the two organisations worked. For Promoter 4 this is feminist, riot-grrrl informed politics in which ideas about promoting women both as musicians and audience members have long held 
important sway. In this context, sexual harassment and violence have been an acknowledged problem within the live music scene, since at least the 1990s, with measures taken to ensure men who abused women were ejected from venues (Downes, 2012). Promoter 4 believed they held themselves to a higher standard than other promoters in the city, in part because of the expectations placed upon them. For instance, with regards to whether they would put on gigs in one particular venue, the fact that just one of their audience had had a bad experience there was enough for Promoter 4 to say it was too high a risk to their reputation:

Well I think other organisations and promoting bodies wouldn't be looking at it in such a like hypercritical, 'oh but this thing happened to this one person that I know in the last twelve months and I know that they personally would be upset if we use that venue'. [...] Whereas we look at it like that cause we're like, 'that's a person in our community' and that is important to us. (Promoter 4)

Care for the individual was therefore an essential part of maintaining their place in the community. Venue 1 shared a "lefty, progressive" (Venue 1) politics with Promoter 4 and our interviewee characterised staff as left wing and coming "from a point of care and from a point of empathy and [...] genuine [...] concern for people" (Venue 1). This is not to say that the other venues we spoke to do not care about their audiences, but to highlight the discourse of care for the individual that Venue 1 and Promoter 4 utilised. It is therefore significant that our two interviewees, who aimed to establish safe spaces at their events, had political beliefs which are underpinned by feminist ideals and practices. In contrast, the male manager of Venue 2's political position might be characterised as the banal politics of the male, white, straight majority (Woodward, 2004). And it is notable that it was this manager that needed persuading by his female staff member to take action. Being beholden to the community through shared feminist and left-wing politics therefore acted as a valuable impulse.

\section{Engaging with oversight organisations}

GNO venue training costs money. While not a large amount of money in comparison to corporate training, venues still need to cover the cost. Furthermore, staff will need to be paid for their time to attend the training, and with the majority of small venues experiencing significant challenges to maintaining financial viability (Webster et al., 2018), and local promoters often operating at a loss, covering the costs of training is not necessarily straightforward. Venues 2 and 3 were able to pay for training from their existing running costs, although neither had a specific staff training budget. Venue 2 recognised their unusual position in the world of independent music venues because, whilst most struggle financially, this was not the case for them. Venue 3 is part of a corporate chain, which meant that there was a source of funds available that was not available to other venues. We do not know if a lack of funds deterred other small venues from seeking training (we were unable to speak to them), and it is likely that there was more than one factor in deciding whether or not to contact GNO. That said, lack of funds can be a barrier to accessing training for smaller music organisations: evidence from promoters indicates that access to external funding can make all the difference, and that is why engaging with oversight organisations such as local authorities is important. 
The training attended by Promoters 2 and 4 was funded by Music:Leeds who recognised that promoters could not individually afford to pay for training themselves. They accessed Arts Council funding to fund a training session for promoters. For the promoters we spoke to this was the only manner in which they could envisage accessing GNO training:

We couldn't afford to pay to do Good Night Out training just for us in the same way that a venue would get trained. So when this opportunity came up where we could just send a couple of people and get trained alongside a load of other promoters in Leeds, that was an opportunity that we had to take up. [...] And that's why Music:Leeds funded it, to make it accessible to DIY promoters cause everybody in that room, not a single one of them would have paid Good Night Out themselves to get trained. (Promoter 4)

Similarly, recognising the financial difficulties faced by small venues, one local authority in our study also offered to pay for two small venues to access training, hoping that they would then act as role models for other venues in the area. The funds came from their cultural development fund, and they were able to supply this funding as it fits in with their agenda of building a sustainable, accessible local music industry. In London, various boroughs worked with GNO, identifying venues who would benefit from training, and then funding training either wholly or in part. The other local authority in our study did not pay for GNO training, as they offered their own in-house training around child sexual exploitation and domestic violence. This did not include much about sexual harassment and violence, but it was nevertheless well-received by music venues and venue 4 did find it useful in helping to develop their relationship with their clientele. The local authority was thinking about what more their in-house training may be able to do around sexual harassment.

Our case studies show the importance of both having available funds to pay for training, and also the existence of some sort of organisation in a position of having a broader interest in culture and/or safety in the area. With independent music venues and promoters typically so financially stretched, for some organisations it is only through third party funding that they are able to access training. Our work in the region enabled attention to be brought to the issue of sexual violence and what those oversight bodies could do about it - fund training or amend their in-house training. Through this, we were able to promote community education (level two of activities on the spectrum of prevention) to these organisations, and also change organisational practices (level five on the spectrum) as they made budgetary decisions. Conversations with local authorities and charities show that there is potential for influencing requirements for training security staff, and amending licensing laws to include duties of care around protection from sexual harassment and violence. This is level six of Davis et al.'s spectrum of prevention, but we argue that to be effective in the music context, such organisations should work in coalition (level four of the spectrum) to maximise their resources and existing networks in achieving more fundamental change.

\section{Driven individuals with power}

Across the venues and promoters we spoke to who had accessed GNO training, one important factor was held in common: it was individuals who felt the need to do something that drove these changes. At Venues 2 and 3, it was women in positions of relative power that made the case to their managers. It is striking that 
both the managers at Venues 2 and 3 spoke of their personal experiences of harassment in a broader gendered context:

Someone said to me, 'Have you ever been hassled on a night out?' and I'm like, 'Yes. I don't think you'll find any woman that's not been hassled at some point, in some way, shape or form on a night out'. (Venue 3)

I'm a female who has always loved music so I'm aware of it anyway. (Venue 2)

Making the connection with other women utilised a feminist theoretical underpinning, and yet it also enabled them to, in some ways, downplay the direct personal impact of their experiences. We could perhaps understand the women as wanting to present themselves as being able to handle such incidents, but indicating that other women might not be, and therefore be requiring of protection. They took on the role of advocates for those women. Nevertheless, in at least one of those venues it required some work on the part of the female manager to convince her own (male) manager:

It just matters. It's so much part of this world now that we should be thinking about it. And that's the conversation that [male manager] and I had eighteen months ago or whatever. It was like, 'well this matters, it's real, we've been told it's a real thing. Well let's start making steps, let's be on the right side of history', as grand and ridiculous as that sounds. [...] Why wouldn't you? That's all I just kept saying was, 'why wouldn't we do this? Why would we not do this?' (Venue 2)

The female manager used arguments around being on "the right side of history", implying to her manager that the reputation of the venue would be at stake if they did not take action. Within this, we can see traces of a post-\#metoo (Burke, 2007; Flood, 2019b) discourse in which there is a hint of fear of being outed as supporting sexual violence. These arguments clearly worked (the venue did access GNO training), but apparently it was not an overnight decision: it took some labour by the female manager to convince her boss.

On the other hand, Venue 4 only sought training after a delegation of female and trans friends of the venue manager approached him and told him that they were thinking of no longer coming to the venue due to the quantity of sexual harassment they faced:
Me having a connection to someone who was a victim helped for us to put the measures in place because a group of our mates who had their concerns were able to come to me in confidence and comfortably. Whereas I think in the past maybe there hadn't been someone who worked for the club who had been personally affected or had been close to someone who's personally affected. But yeah it was a group of people who had a concern, who really loved the club and were concerned that it was going in the wrong direction. And teamed together to express their concerns. (Venue 4)

Similarly, Promoter 2 had been galvanised by an upsetting incident of assault at one of the gigs he promoted, and the subsequent feeling of powerlessness from not knowing how to respond. As the director of the organisation, he was in a position to take action on accessing training, and felt that this fitted in with the broader ethos of the organisation with respect to inclusivity. Personal experience is therefore a 
vital factor in catapulting a venue or promoter towards making changes, and this includes hearing directly from women who have suffered violence (Flood, 2019a). Burrell argues that there is a direct link between men listening to women and reflecting on their own behaviour: "If men are not listening, then they are unlikely to change. However, the same is also true if they at no point feel challenged or uncomfortable by work which seeks to deconstruct their power and privilege" (Burrell, 2018: 456).

Flood (2019a: 126) notes that too often men see violence against women as a "women's issue", shifting responsibility to women to solve the problem rather than being prepared to examine their own behaviour. That the majority of those driving changes were women, and that they intimated they had been subjected to sexual violence in the past, is significant, but, in this light, unsurprising. It is sad that it requires these kinds of experiences to move towards change, but we must also flag up men's feelings of powerlessness in the face of incidents. A previous interview with a male manager at Venue 3 revealed a lack of knowledge and skill of what to do when sexual violence happened on the premises. Offering the chance for venues and promoters to strengthen the knowledge and skills of individuals in the organisation - Davis et al.'s (2006) level one - was a positive way in which to put upsetting experiences to work. Men's feelings may interact with ideations of the masculine self as someone who knows what to do and is able to protect women. GNO's training includes developing skills around being a positive bystander who is able to intervene when they see something untoward. The venues and promoters spoke of this aspect of the training in especially favourable language, describing it as having engendered greater "compassion" (Venue 4) amongst staff, as Venue 2 told us:
There was a leechy horrible fella chatting to a group of young girls. [...] And they were all just looking a bit uncomfortable. So [X] who's one of the male supervisors walked over [...] and said, 'hey ladies, everything okay here?' And they were like, 'no he's weird'. And so [X] just went, 'cool, you're freaking them out, you're going to need to move', and he just got up and moved to the other part of the building. And then we kept an eye on him all night, the staff spoke about it and he behaved. So that's just straight up, it's something that we wouldn't have intervened in previously I think. Cause you don't see it, but if you saw someone getting grabbed or something everyone's like, 'oh that's horrible', whereas there's the subtle stuff that I think prior to that training people didn't know. (Venue 2)

There is a risk, however, that bystander intervention may play into more traditional passive/active roles. But where the focus is placed on masculinity and men supporting other men to develop new masculinities, there is the potential to "problematis[e] hegemonic masculinity" (Powell and Henry, 2014: 7). A typical GNO training session may not have the scope and time to unpick a lifetime's immersion in masculine ideals, but enabling staff to be able to spot what counts as men's unacceptable behaviour that makes women uncomfortable is a good start, we think.

With that in mind, we felt that WR's tactic of men talking to other men could be a valuable mode of communication. We were disappointed that it was not more widely taken up by venues. This could have been because, as Venue 2's female manager explained, WR's requirements were seen to be tailored towards larger venues with clear hierarchical structures, rather than small venues with limited time and resources. The action plan placed too much responsibility on a single person (a nominated WR Ambassador - a man in a leadership role in the venue) when 
such a person was already likely to be very stretched. Given that WR's approach is the only one that directly addresses men, and that music venues are often maledominated places, it strikes us that WR could play a key role in convincing venues to take action. However, a revised approach that works in the specific context of small venues would be needed.

The duality of individual, localised efforts towards effecting gender equality, and those facilitated and supported by more systemic structures is demonstrated by de Boise (2017: 486) who compares the "arm's-length", market-based approaches of the UK with the "cultural democratic" interventionist approaches of Sweden. De Boise describes Sweden's direct implementation of gender mainstreaming into cultural policy and central government initiatives which, through greater financial and policy support for gender equality initiatives, can legitimise localised efforts and address more structural concerns of gender disparities. In the UK, individual localised efforts may fall short due to a lack of support from local or central government. This "systemic disinterest" (de Boise, 2017: 496) can exacerbate issues and, in the current austerity conditions, may lead to a reversal of progress. The UK might learn from Sweden, therefore, to develop the role of government to champion the exceptional examples - whether organisational or individual - of cultural change. The grassroots music scenes of the UK have a heavy reliance on volunteer labour in precarious financial circumstances, with training adding to costs. If the UK music scene is to continue to tackle gender inequalities from a market-based approach, then structural, financial, and policy support from state institutions are required.

\section{Conclusion}

Working towards gender equality in local music scenes, and implementing changes such as integrating sexual violence training, requires activity across a range of levels: activities at levels from the individuals employed in music venues through to those with power in music venues, and those who are in a position of oversight with access to funds. These are important pieces of the jigsaw when it comes to persuading for change and being able to act on those impulses. Networking and a sense of community across and within music scenes are beneficial for providing the rationale for accessing training and making change. Webster et al. (2018) found that, whilst there is competition between venues for customers, the success of a scene requires that venues support one another. Our research provides evidence of how venues do work with one another across a scene, but also the limitations of 'Community', especially when politics and identity positions differ. We regard Venue 1 as doing good anti-violence work in the city. They recognise their limitations and reflect on their processes; their safer spaces agreement is always in process; the policy is built into the day-to-day running of the venue. For other venues and promoters to enjoy greater engagement with Venue 1, without putting undue pressure on their resources, would be a good outcome. We believe that raising awareness of what kinds of behaviour are inadmissible across a majority of venues would lead to a safer and more pleasurable local music industry for those typically on the receiving end of sexual violence.

As we have also argued, women play a vital role in establishing a need for change, and in persuading those with power that change is necessary and achievable. Drawing on our own experiences, and the experiences of those around us, is very important for inspiring the need for change. We would also argue that being presented with implementable changes in the form of training, procedures, 
and policy also matters. As we have explored, however, there is a tension here with the male dominance of the music industry. For the manager at Venue 2, for example convincing her boss took work, work which was assisted by the relationship she had with the research team as we discussed the findings of the research with her in formal and informal meetings. There are two things that need to happen: (one) men in the music industry need to become more aware of the need for change, and be willing to act on that awareness; (two) more women need to own, manage, and play key roles in the running of venues and events. Whilst training and engagement across the community can help to achieve the first of these, the second is a different matter. Ultimately, we have argued that challenging norms that enable sexual violence to occur, and learning to deal well with incidents when they do happen, is achievable for the grassroots music industry. Engaging in these processes is an important and valuable means to address one of the causes of the exclusion of women and gender non-conforming people from, and inequality within, the music industry, and has the potential to play a part in changing norms of sexually predatory behaviour more broadly.

\section{Endnotes}

(1) Many thanks to one of the reviewers for this valuable information.

(2) Promoters 1 and 3 from the first phase of the research did not participate in phase 2.

(3) Peace, Love, Unity and Respect (PLUR) is an underpinning philosophy of rave culture and encourages caring and respectful relations between participants. It has its roots in hippy culture and was written as a Ravers Manifesto in 2001 by Maria Pike (2001/2015). Whilst the philosophy is a happy ideal, Fiona Hutton (2006) exposes how the ideal is used to perpetrate unwanted sexual touching to which women feel unable to object.

\section{References}

\section{Bibliography}

Arango DJ, Morton M, Gennari F, et al. (2014) Interventions to prevent or reduce violence against women and girls: A systematic review of reviews. Women's Voice and Agency Research Series 10: 1-61.

Bain V (2019) Counting the music industry: the gender gap. October 2019. Available at: https://countingmusic.co.uk/ Accessed 20 October 2020.

Battersby C (1989) Gender and genius: towards a feminist aesthetics. London: The Women's Press.

BBC News (2018) 'Shocking' level of sexual harassment at music festivals. In: BBC. Available at: https://www.bbc.co.uk/news/entertainment-arts-44518892 (accessed 20 October 2020).

Bennett T (2018) "The whole feminist taking-your-clothes-off thing": negotiating the critique of gender inequality in UK music industries. IASPM Journal 8(1): 24-41.

Brooks O (2011) 'Guys! stop doing it!': young women's adoption and rejection of safety advice when socializing in bars, pubs and clubs. The British Journal of Criminology 51(4): 635-651.

Burke T (2007) The inception. In: Just Be Inc. Available at: http://justbeinc. wixsite.com/justbeinc/the-me-too-movement-cmml. 
Burrell SR (2018) The contradictory possibilities of engaging men and boys in the prevention of men's violence against women in the UK. Journal of GenderBased Violence 2(3): 447-464.

Butler J (1993) Bodies That Matter: On the Discursive Limits of Sex. Farnham: Routledge.

Conor B, Gill R and Taylor S (2015) Gender and creative labour. The Sociological Review 63(S1): 1-22.

Dagens Nyheter (2017) 2192 women in the Swedish music industry behind appeal against sexism. Dagens Nyheter, 22/11/2017. Available at: https://www.dn.se/kultur-noje/2192-women-in-the-swedish-music-industrybehind-appeal-against-sexism/. Last accessed 20 October 2020

Davis R, Parks LF and Cohen L (2006) Sexual violence and the spectrum of prevention: Towards a community solution. National Sexual Violence Resource Center Enola, PA.

de Boise $S$ (2017) Tackling gender inequalities in music: a comparative study of policy responses in the UK and Sweden. International Journal of Cultural Policy 2(4): 486-499.

DeGue S, Valle LA, Holt MK, et al. (2014) A systematic review of primary prevention strategies for sexual violence perpetration. Aggression and Violent Behavior 19: 346-362.

Downes J (2012) The expansion of punk rock: riot grrrl challenges to gender power relations in British indie music subcultures. Women's Studies 41(2): 204-237.

Enloe C (2017) The big push: exposing and challenging the persistence of patriarchy. Oxford: Myriad.

Evans M (2017) The persistence of gender inequality. Cambridge: Polity.

Fileborn B (2016) Reclaiming the night-time economy: unwanted sexual attention in pubs and clubs. London: Palgrave Macmillan.

Fileborn B, Wadds P and Barnes A (2019) Setting the stage for sexual assault: the dynamics of gender, culture, space and sexual violence at live music events. In: Strong C and Raine S (eds) Towards gender equality in the music industry: education, practice and strategies for change. London and New York: Bloomsbury.

Fileborn B, Wadds P and Tomsen S (2020) Sexual harassment and violence at Australian music festivals: Reporting practices and experiences of festival attendees Australian and New Zealand Journal of Criminology 53(2): 194-212.

Flood M

(2019a) Engaging men and boys in violence prevention. New York: Palgrave Macmillan.

(2019b) Men and \#MeToo: mapping men's responses to anti-violence advocacy. In: Fileborn B and Loney-Howes R (eds) \#MeToo and the politics of social change. Cham, Switzerland: Palgrave Macmillan, pp.285-300.

Gavey N (2005) Just sex?: the cultural scaffolding of rape. Hove: Routledge.

Goldman JA and Harlow LL (1993) Self-Perception Variables That Mediate AIDSPreventive Behavior in College Students. Health Psychology 12(6): 489-498.

Grossberg L (1984) Another boring day in paradise: rock and roll and the empowerment of everyday life. Popular Music 4: 225-258. 
Gunby C, Carline A and Taylor S (2017) Location, libation and leisure: an examination of the use of licensed venues to help challenge sexual violence. Crime Media Culture 13(3): 315-333.

Hester M, Kelly L and Radford J (1996) Women, violence and male power. Buckingham: Open University Press.

Hill RL, Hesmondhalgh D and Megson M (2020) Sexual violence at live music events: experiences, responses and prevention. International Journal of Cultural Studies 23(3): 368-384.

Hill RL and Megson M (2020) In defence of safer spaces: punk, privilege and safer spaces policies. Punk \& Post-Punk 9(1): 59-76.

Hong L (2000) Toward a transformed approach to prevention: Breaking the link between masculinity and violence. Journal of American College Health 48(6): 269-279.

Hutton F (2006) Risky pleasures? Club cultures and feminine identities. London: Routledge.

Johnston M (2016). Kesha and Dr. Luke: everything you need to know to understand the case Rolling Stone, 22 February. Available at: https://www.rollingstone.com/music/music-news/kesha-and-dr-luke-everythingyou-need-to-know-to-understand-the-case-106731/. Accessed 20 October 2020.

Katz J (2006) Macho Paradox: Why some men hurt women and and how all men can help. Sourcebooks, Inc.

Kelly L (1988) Surviving sexual violence. Cambridge: Polity.

Kemmis S, McTaggart R and Nixon R (2014) The action research planner: doing critical participatory action research. Singapore: Springer.

Latané B and Darley JM (1970) The unresponsive bystander: why doesn't he help? Englewood Cliffs: Prentice-Hall.

Leonard M (2016) Girls at work: gendered identities, sex segregation and employment experiences in the music industries. In: Warwick J and Adrian A (eds) Voicing Girlhood in Popular Music: Performance, Authority, Authenticity. New York: Routledge, pp.37-55.

Lubet A (2011) Music, disability, and society. Philadelphia: Temple University Press.

Mackenzie J (2017) Rape and abuse: The music industry's dark side exposed. $B B C$. Available at: https://www.bbc.co.uk/news/entertainment-arts-42368544 (accessed 16/10/2020).

Madden E (2019) I was sexually assaulted at Reading Festival in 2010: Has anything changed since? The Telegraph, 22/08/2019. Available at: https://www.telegraph.co.uk/music/news/sexually-assaulted-reading-festival2010-has-anything-changed/ Accessed 20 October 2020.

Michau LMA, Horn JM, Bank ABA, et al. (2015) Prevention of violence against women and girls: lessons from practice. Lancet, The 385(9978): 1672-1684.

Moskovitch G (2015) Victoria sets up taskforce to tackle harassment of women at gigs. Tone deaf. Available at: https://tonedeaf.thebrag.com/victoria-sets-uptaskforce-to-tackle-harassment-of-women-at-gigs/ (accessed 20 Oct 2020).

Musicians' Union (2019) Preventing sexual harassment at work, protecting freelancers too. Musicians' Union. Available at: https://www.musiciansunion.org.uk/Home/News/2019/Oct/Preventing-SexualHarassment-at-Work-Protecting-Fr (accessed 20 Oct 2020). 
Musicians' Union (n.d.) MU safe space scheme. Available at: https://www.musiciansunion.org.uk/safespace (accessed 17/08/2020).

O'Connor R (2017) Architects singer Sam Carter calls out man 'who grabbed fan's breast while she was crowdsurfing'. The Independent, 19 August. Available at: http://www.independent.co.uk/arts-entertainment/music/news/architects-gigsam-carter-crowdsurfer-video-lowlands-festival-sexual-assault-grope-latesta7901606.html Accessed 20 October 2020.

Pearce R and Lohmann K (2019) De/constructing DIY identities in a trans music scene. Sexualities 22(1-2): 97-113.

Pease B (2014) Theorising men's violence prevention policies: limitations and possibilities of interventions in a patriarchal state. In: Henry $\mathrm{N}$ and Powell $\mathrm{A}$ (eds) Preventing sexual violence: interdisciplinary approaches to overcoming a rape culture. Basingstoke: Palgrave Macmillan, pp.22-44.

Pike M and Bones F (2001/2015) The raver's manifesto. Available at: https://frankiebones.tumblr.com/post/124796352418/the-ravers-manifesto/amp (accessed 19/08/2020).

Platt L and Finkel R (2020) Gendered violence at international festivals: An interdisciplinary perspective. Abingdon: Routledge.

Potter S (2019) Making spaces safer: a guide to giving harassment the boot wherever you work, play, and gather. Chico, CA and Edinbugh: AK Press.

Powell A and Henry N (2014) Framing sexual violence prevention: what does it mean to challenge a rape culture? In: Henry $\mathrm{N}$ and Powell A (eds) Preventing sexual violence: interdisciplinary approaches to overcoming a rape culture. Basingstoke: Palgrave Macmillan, pp.1-21.

Sharp M and Nilan P (2017) Floorgasm: Queer(s), solidarity and resilience in punk. Emotion, Space and Society 25: 71-78.

Strong C and Raine S (2018) Gender politics in the music industry. IASPM Journal 8(1): 2-8.

Timonen S (2018) Sexual misconduct in the music industry: then and and now. Paper at the IASPM UK and Ireland Biennial Conference Crosstown Traffic: Popular Music Theory and Practice, Huddersfield, UK. Available at: https://www.youtube.com/watch?v=8Rr7NLTbuQA Accessed 20 October 2020.

Vera-Gray F (2017) Men's intrusion, women's embodiment: a critical analysis of street harassment. Abingdon: Routledge.

Walby S (1990) Theorizing patriarchy. Oxford: Basil Blackwell.

Webster E, Brennan M, Behr A, et al. (2018) Valuing live music: the UK live music census 2017 report. Available at: http://uklivemusiccensus.org/ (accessed 17/08/2020).

Woodward K (2004) Questioning identity: gender, class, ethnicity. London: Routledge.

\section{Web Sources}

Good Night Out Campaign (2020) About Us. Available at: http://www.goodnightoutcampaign.org/about/ (Accessed 30/01/2020).

Girls Against Gig Groping (2020) Girls Against Available at: https://www.facebook.com/girlsagainstgroping/ (accessed 14/08/2020). 
Safe Gigs For Women (2017) Safe Gigs For Women. Available at: https://sgfw.org.uk/ (accessed 14/08/2020).

White Ribbon Campaign UK (n.d.) What we do. Available at:

https://www.whiteribbon.org.uk/what-we-do (accessed 07/02/2020). 